\title{
Using Eccentrically Sample to Find the Relationship between Resistivity and Cracking Time in Cement Paste Vides Mechanical Strength and Electrical Resistivity
}

\author{
Maha. A. Abusogi, WEI Xiaosheng* , Fu lei \\ School of Civil Engineering and Mechanics, Huazhong University of Science and Technology, Wuhan, China \\ *Corresponding author: victorwei@ hust.edu.cn
}

\begin{abstract}
Early-age cracking is often attributed as a major cause of reduction in the durability of concrete structures. The objective of this paper is to study the hydration behavior of various samples of different water-cement ratios, that's in order to assess crack potential, compressive strength and setting time of the cement paste. The behavior of hydration was monitored by using a non-contact electrical resistivity apparatus. While a new eccentrically steel cracking frame (ESCF), setting time and compressive strength standard test were considered to measure the restrained shrinkage cracks, compressive strength and setting time respectively. The objective of using the eccentrically sample is to provide a new method to assess the cracks at early age by presents a complicated and non-uniform circumferential stress in the eccentrically cement paste ring. The results show that the electrical resistivity measurement of all samples with different water cement ratios had similar trends. Whereas the lowest water-cement ratio paste indicates highest resistivity values, reaches an earlier inflection point, and obtained higher compressive strength than other cement pastes of higher water-cement ratio. The eccentrically restrained cracking test (ERCT) and setting time demonstrated that lower water-cement ratio paste set and cracked earliest, which is therefore, confirmed its highest cracking tendency. The cracks took place at the narrow regions of specimens, which can be an indicator for eccentrically restrained shrinkage test (ERST). The cracks were observed as growing at narrow areas and reach full-depth over time. A mathematical model for predicting the cracking age of cement is proposed. The equation showed the existence of a positive relationship between electrical resistivity represented by inflection points (Ti) and cracks time (Tc).
\end{abstract}

Keywords: eccentrically steel cracking frame, eccentrically restrained cracking test, eccentrically restrained shrinkage test

Cite This Article: Maha. A. Abusogi, WEI Xiaosheng, and Fu lei, "Using Eccentrically Sample to Find the Relationship between Resistivity and Cracking Time in Cement Paste Vides Mechanical Strength and Electrical Resistivity." American Journal of Civil Engineering and Architecture, vol. 5, no. 4 (2017): 154-159. doi: 10.12691/ajcea-5-4-3.

\section{Introduction}

Construction of some structures requires large volume of concrete. Due to the small surface area-to-volume ratio, concrete structures are often subjected to high potential of thermal cracking, caused by heat generation from cement hydration process. Generally, cracking is most prominent in structures with a large surface area to the volume ratio, including slabs-on-grade, tunnel lining and overlay [1].

Cracking is considered as a major problem that accelerates deterioration and reduces the capacity of carrying loads, which in return, shortens the service life of concrete structures and increases maintenance cost. A study from American society of civil engineering reported that the annual cost of concrete repair and rehabilitation was estimated to be $1.8 \$$ to $2 \$$ billion in 2006 [2].

Shrinkage cracks also referred to the volumetric contraction of cement paste materials that occur during the first few hours after placement, while the material is in a plastic state. The contraction is driven by a combination of autogenous mechanism and capillary pressure that develops in the porous structure near the surface when the rate of water evaporation from the mixtures exceeds the rate at which it can be replaced by rising bleed water $[1,3]$.

Previous reports published from various state Departments of Transportation (DOTs) in United States conclude that the shrinkage is the major contributing factor to early age cracking and continues to contribute over long duration after concrete hardening $[1,4,5]$. The potentiality of a cementitious mixture to crack is influenced by many factors such as the quantity of cement, water and admixture, along with the surrounding drying conditions such as temperature, relative humidity, age of concrete at which it is subjected to drying, size/geometry of the structure and degree of restraint [6]. When cementations mixtures are restrained from shrinkage the tensile strength will be induced. If these stresses exceeded the tensile strength of the considered mixture it leads to cracks. Such 
initially shallow cracks can grow to full depth over time and jeopardize the structure's integrity [3].

Many researchers have developed simple tests to assess and evaluate the cracking tendency of concrete $[7,8,9]$. Many others have considered the crack tendency with restrained shrinkage in their studies for the assessment of concrete cracking problems $[10,11]$. Some of those researchers followed the standard procedure for the determination of cementitious materials crack prediction due to restraint as provided under AASHTO specification 1997 [12].

Recently, researchers have widely applied the circular ring test to measure concrete cracks and other cement-based materials. It is comparatively easy to commence such test since the standard dimensions of circular ring specimens are similarly recommended by AASHTO and ASTM. In addition, few theoretical and numerical models were formulated to figure residual stress development and cracking age of concrete in restrained circular ring specimens.

In this study, a novel eccentrically ring geometry is adopted for evaluating cracking of cement paste materials under restrained condition. The samples and prediction of the cracks in this test is quite different from that of ring specimens. In a circular ring specimen, restraining effect from the central steel ring to the surrounding concrete ring is uniform along its circumference. Accordingly, this will lead to uniform peripheral tensile stress in the concrete ring on its circumference. Hence, the barely restraining result of the central steel ring on the adjacent concrete can be conveniently substituted by a fictitious uniform pressure applied on the internal surface of the concrete ring in analytical/numerical analyses [8]. Contrariwise, the eccentrically sample produces a complicated and nonuniform circumferential stress in the eccentrically cement paste ring. Consequently, a closed-form analytic solution is not available for predicting residual stress development in eccentrically geometry cement paste ring subject to restrained shrinkage.

In this paper, all experiments were conducted to focus on the hydration process of cement pastes with different water to cement ratio using non-contact electrical resistivity measurement, volume deformation (cracks) by restrained shrinkage, mechanical strength and the relation between the strength at early age against resistivity.

\section{Objectives}

The present work aims to study the hydration behavior of various water-cement ratio pastes to be monitored using a non-contact electrical resistivity apparatus. Similarly, the volume deformation of a new eccentrically steel cracking frame (ESCF) used to monitor the early cracks of the cement pastes. The objective of using the eccentrically sample is to provide a new method to assess the cracks at early age by presence of a more complicated and non-uniform circumferential stress in the eccentrically cement paste ring. Then measuring the compressive strength and setting time by following the standard procedure to conduct the test.

\section{Materials and Experimental Methods}

\subsection{Materials}

Ordinary Portland cement P.0 42.5 that meets the requirements of Chinese cement standard GB/ T176711999 was used. The chemical composition of the cement as determined by using the $\mathrm{X}$-ray fluorescence is presented in Table 1 .

Table 1. Chemical composition of Portland cement

\begin{tabular}{|c|c|c|c|c|c|c|c|c|}
\hline Composition & $\mathrm{CaO}$ & $\mathrm{SiO}_{2}$ & $\mathrm{Al}_{2} \mathrm{O}_{3}$ & $\mathrm{Fe}_{2} \mathrm{O}_{3}$ & $\mathrm{MgO}$ & $\mathrm{Na}_{2} \mathrm{O}$ & $\mathrm{K}_{2} \mathrm{O}$ & $\mathrm{SO}_{3}$ \\
\hline $\begin{array}{c}\text { Mass } \\
\text { fractions \% }\end{array}$ & 65.22 & 19.28 & 5.88 & 3.46 & 1.16 & 0.1 & 0.12 & 1.87 \\
\hline
\end{tabular}

Four different cement pastes with water to cement ratios of (W/C) $0.3,0.35,0.4$, and 0.45 were prepared and were denoted as $\mathrm{P} 0.3, \mathrm{P} 0.35, \mathrm{P} 0.4$, and $\mathrm{P} 0.45$ respectively (see Table 2). All the pastes were mixed with regular drinking water.

Table 2. Mix ID and water to cement ratio

\begin{tabular}{|c|c|c|c|c|}
\hline Mix ID & P0.3 & P0.35 & P0.4 & P0.45 \\
\hline W/C & 0.3 & 0.35 & 0.4 & 0.45 \\
\hline
\end{tabular}

\subsection{Experimental Methods}

\subsubsection{Electrical Resistivity Measurement}

In this study, electrical resistivity of the cement paste was measured using a non-contact electrical resistivity apparatus as depicted by X. Wei and Z. Li [13], as shown in Figure 1. Samples were produced in room surroundings conditions in which the temperature and humidity were $20 \pm 2 \mathrm{C}^{\circ}$ and $98 \pm 2 \%$ respectively. The pastes were mixed at $45 \mathrm{rpm}$ for 3-4 minutes and then cast into ring-shaped plastic moulds. The specimens were covered with lids in order to achieve an enclosed system and prevent water evaporation. Electrical resistivity measurement was adopted to monitor the hydration behavior of the prepared cement samples. Four different samples were tested for each of the cement pastes in which the average values are reported as the electrical resistivity development for each respective sample.

\subsubsection{Mechanical Strength Tests}

In order to investigate the strength development with age, the compressive strength was measured at 3days, 7 days and 28 days. The samples of cement paste were prepared, mixed and cast into a $40 \mathrm{~mm} \times 40 \mathrm{~mm} \times 40 \mathrm{~mm}$ mould for compressive strength test with different water cement ratio based on the procedure of testing compressive strength of mortar provided by ASTM C109 standard, using hydraulically driven material testing system (MT810) [14] and applied loading of $24 \mathrm{KN} / \mathrm{s}$. The samples were cast and immersed into a curing reservoir until testing age. The curing condition was maintained at a temperature and humidity of $20 \pm 2^{\circ} \mathrm{C}$ and $98 \pm 2 \%$ respectively. 


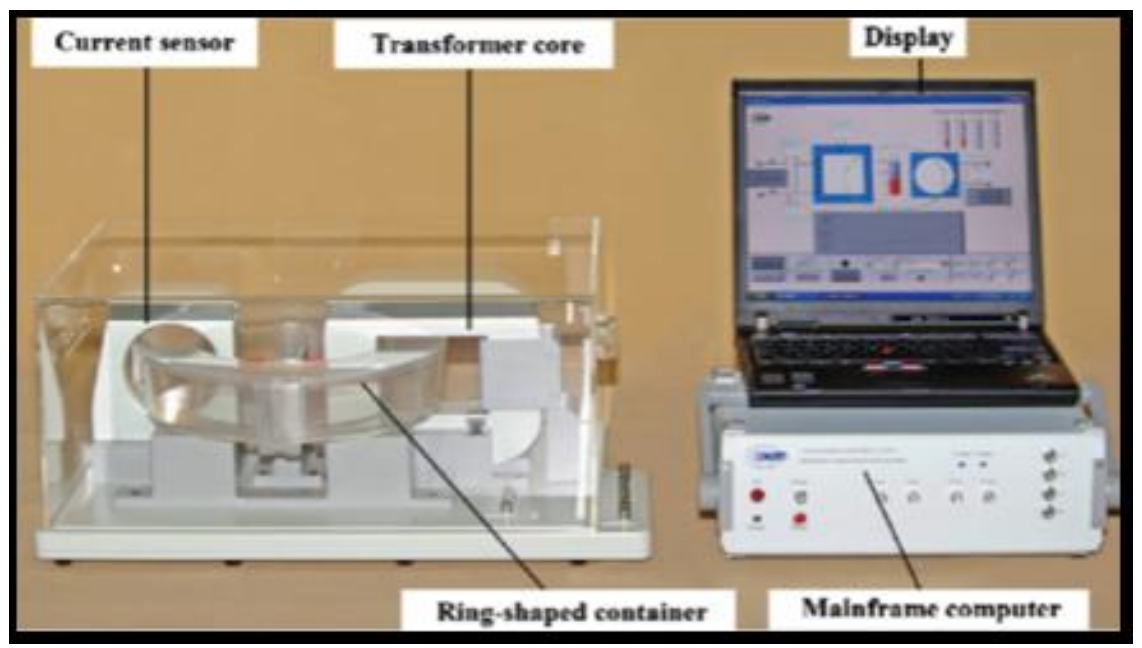

Figure 1. Non-contact electrical resistivity apparatus

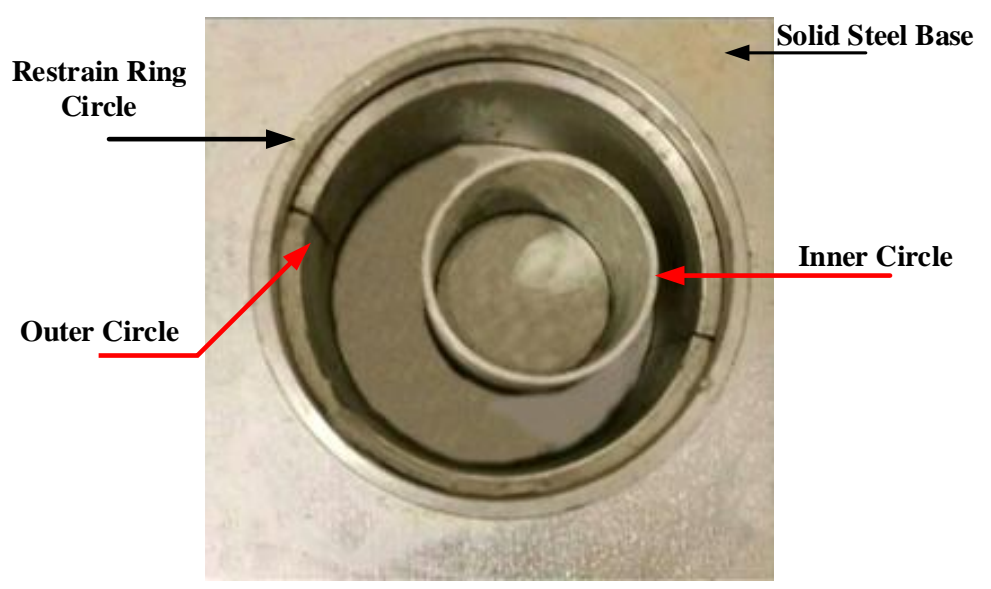

Figure 2a. eccentrically steel cracking frame

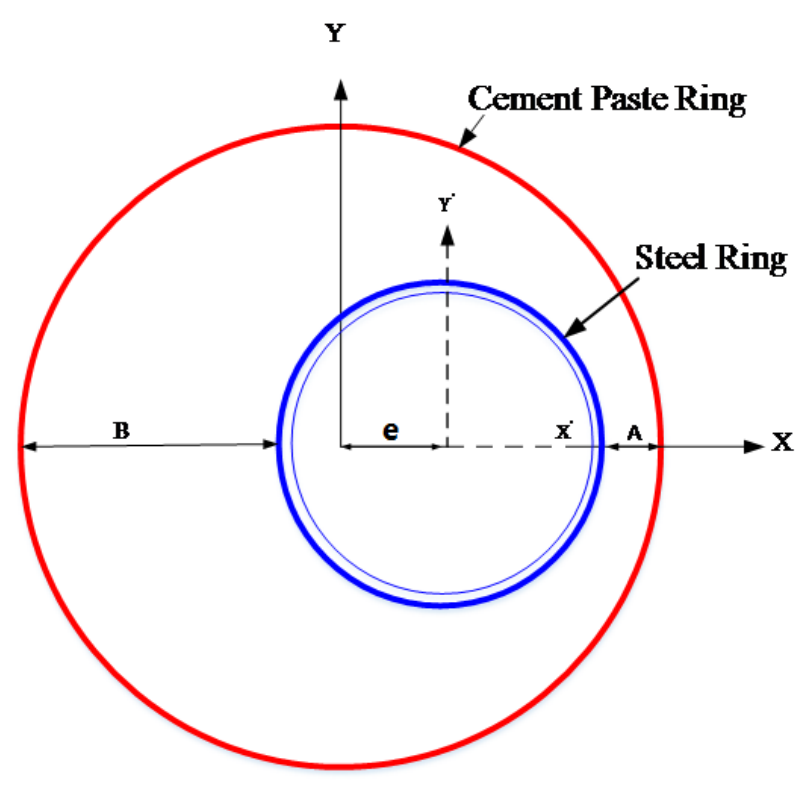

Figure 2b. Restraint shrinkage crack Apparatus

\subsubsection{Volume Deformation (Cracking) Test}

A new eccentrically steel cracking frame shown in Figure 2(a) and (b) was adopted to monitor the restrained shrinkage crack of cement paste samples. Four geometric parts screwed together on a solid steel base as shown in the figures. These parts include 2 circles with different centers in order to create eccentrically samples, the outer circle include two detachable circular parts and inner circle with the small diameter as shown in Figure 2a. Under this experiment samples of P0.3,P0.35, P0.4 and $\mathrm{P} 0.45$ were cast in the apparatus and set in curing room for one day under $20 \pm 2{ }^{\circ} \mathrm{C}$ and $98 \pm 2 \%$ temperature and humidity respectively, after that the two component of the outer circle were removed while the other parts left in place providing restrain to the sample.

\subsubsection{Setting Time Test}

Cement paste samples were prepared and subjected to setting time experiment using Vicat needle apparatus. The sample was gently placed, shacked and compacted into the test ring mould. The test was conducted based on ASTM C191-08 [15], and the needle diameter used in the test was $1.13 \mathrm{~mm}$. In addition, the test condition temperature and humidity were maintained at $20 \pm 2{ }^{\circ} \mathrm{C}$ and $95 \pm 2 \%$ respectively.

\section{Results and Discussion}

\subsection{Electrical Resistivity}

The results from four different mixtures are listed in Table 3 hereinafter. Figure 3 shows the electrical resistivity development $[\rho(t)-t]$ curves for the period of 72 
hours. The result shows that all of the curves followed similar trend to heat evaluation curve of cement; in which the electrical resistivity starts to decrease at the initial stages until reaches trough they started deceasing at the initial stage to the minimum point then gradually increase with time. The lowest water-cement ratio paste has the highest resistivity which as similar to the research finding by S. M. Bawa et al [6].

Table 3. Mix proportion, Setting Time and Compressive strength

\begin{tabular}{|c|c|c|c|c|c|c|}
\hline \multicolumn{2}{|c|}{ Mixtures } & \multicolumn{2}{c|}{ Setting Time (h) } & \multicolumn{2}{c|}{ Compressive Strength (Mpa) } \\
\hline Sample & W/C & Initial & Final & 3 day & $\mathbf{7 ~ d a y}$ & 28 day \\
\hline P0.3 & 0.3 & 6.75 & 7.75 & 45.8 & 64.2 & 71.0 \\
\hline P0.35 & 0.35 & 7 & 8.5 & 32.9 & 45.6 & 58.2 \\
\hline P0.4 & 0.4 & 8.5 & 9.75 & 34.2 & 43.6 & 61.3 \\
\hline P0.45 & 0.45 & 9.95 & 11.3 & 25.7 & 35.9 & 48.4 \\
\hline
\end{tabular}

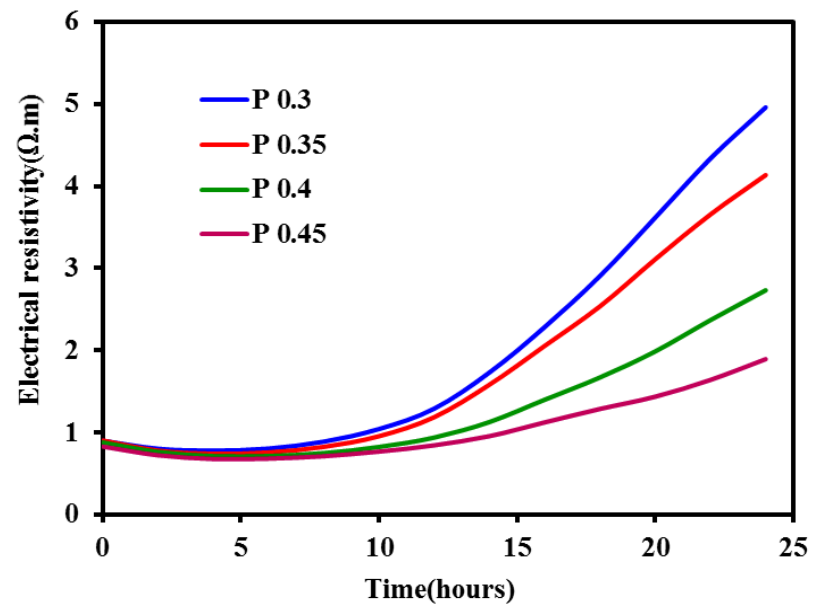

Figure 3. Electrical Resistivity development $[\rho(t)-t]$ curves

The bulk electrical resistivity $(\mathrm{d} \rho(\mathrm{t}) / \mathrm{dt}-\mathrm{t})$ of cement paste samples is displayed in Figure 4. The figure indicates the rate of electrical resistivity development, which shows five periods based on the critical points $\rho \mathrm{m}$, $\rho \mathrm{a}$, $\rho$ i upon which the hydration process is interpreted. These periods are dissolution period (I), an induction period (II), an acceleration period (III), a deceleration and diffusion controlled period (IV), which are similar to the research conducted using different cement types $[13,16,17]$.

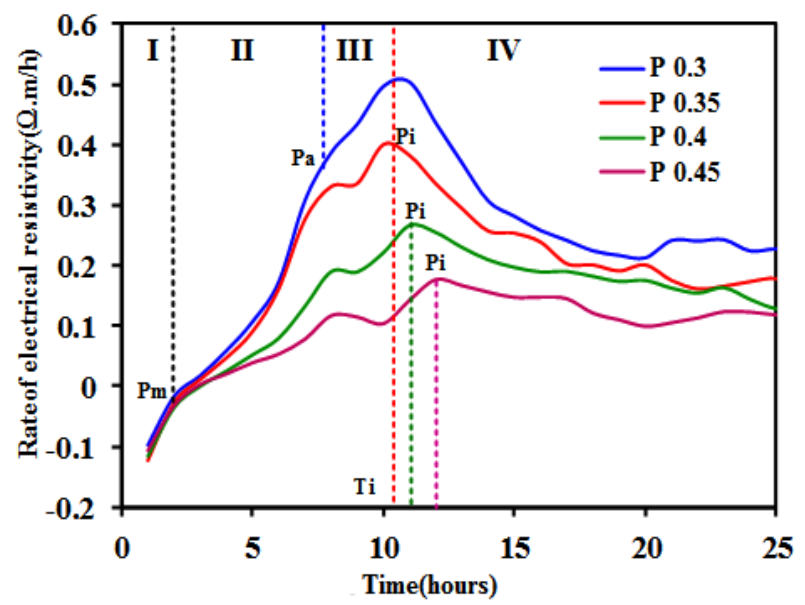

Figure 4. Electrical resistivity derivative curve

\subsection{Setting Time, Compressive Strength Relation with Resistivity}

The properties of porous cement-based material, such as mechanical strength and durability, depend basically on the pore space and morphology of solid phase. The development of electrical resistivity with time reflects the decrease of pore space with conductive ions and the increase of solid space with insulator properties; and such relation can be determined by comparing the electrical resistivity and mechanical properties [18].

Setting time is the duration that a cement paste needs to gain particular strength through its hydration process. As shown in Table 3 , the setting time changes with variation in the w/c ratio. The results shown in Figure 5 illustrates that paste P0.3 has always obtained the earliest initial setting time as well as the earliest final setting time as compared to the other samples (namely P0.35, P0.4 and P0.45).

Figure 5 clearly demonstrates that the increment of w/c ratio has a prolonging effect on the setting time of cement paste (the setting time occurred in period II); corresponding to the rate of resistivity before the first peak's value for all samples.

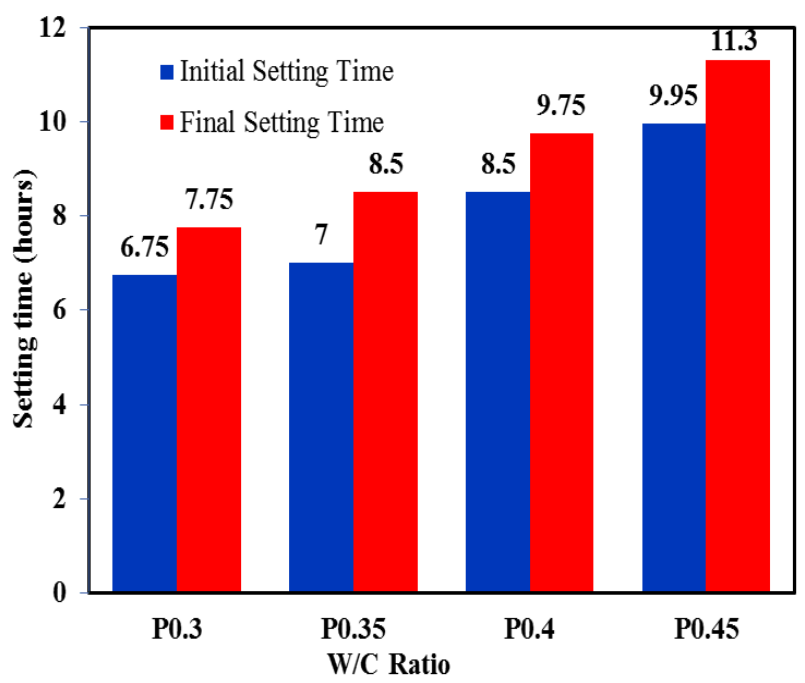

Figure 5. Setting Time for samples with different w/c ratio

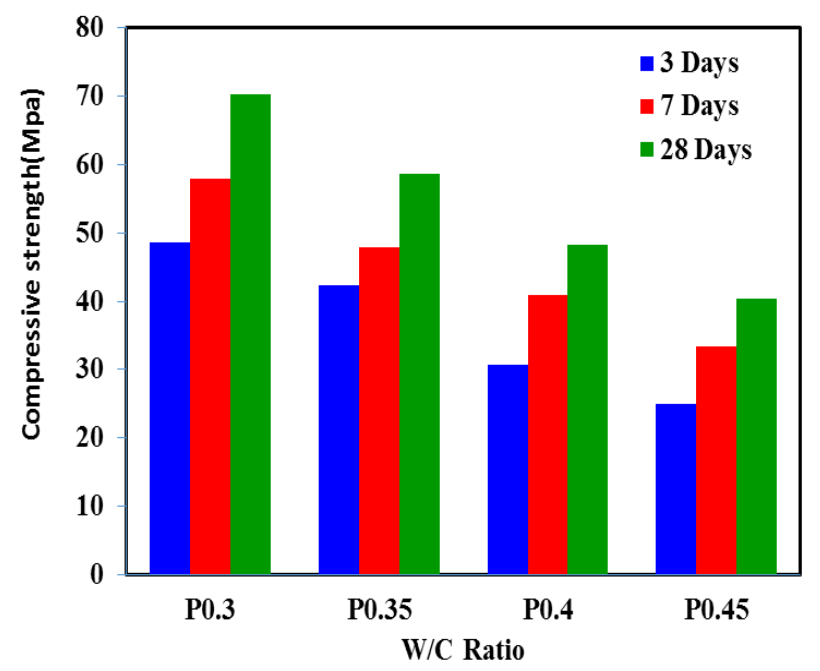

Figure 6a. Compressive Strength of the samples at 3,7and 28days 


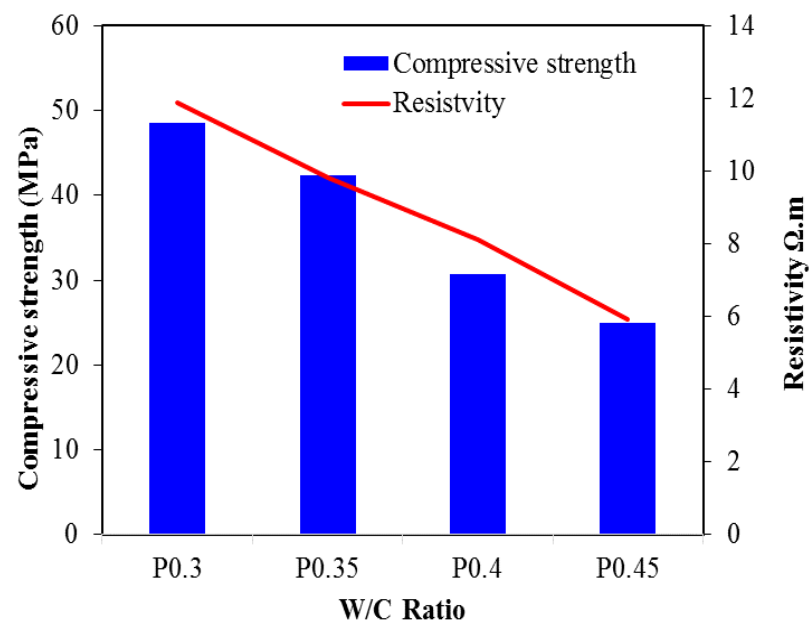

Figure 6b. Compressive Strength and Bulk Electrical Resistivity

The results of compressive strength shown in Table 4 were taken for all samples at different curing periods (namely 3, 7, and 28 days). Compressive strength is one of the most important mechanical properties of cement paste materials. In Figure $6 \mathrm{a}$ it could be seen that the paste P0.3 (of the lowest water to cement ratio) has a higher compressive strength than pastes $\mathrm{P} 0.35$, P0.4, and P0.45 (with a higher w/c ratio) at the age of 72 hours. The relation between compressive strength and electrical resistivity is illustrated in Figure $6 \mathrm{~b}$ where the compressive strength of each paste is measured at 3,7 , and 28 days, the results of lower w/c ratio given the higher compressive strength and resistivity development rate at 72 hours; thus, it can be concluded that there is positive relation between the compressive strength and resistivity.

\subsection{Restrained Shrinkage Cracking Test}

The cracking times $\left(\mathbf{T}_{\mathbf{c}}\right)$ obtained are $(39.70,51.92$, 52.33 and 59.05 hour) for the examined cement pastes as shown in Table 4 . The crack ages is obtained from restrain shrinkage test for all samples then plotted on the graph to find the relationship between cracks' time and inflection time from bulk resistivity.

It is clear that the lower water to cement ratio get the higher rate of drying evaporation and the drop of temperature leads to higher stress development rate, which is rapidly exceeds the tensile strength of the sample; which consequently leads to earliest crack. This result is symmetrical to the findings from previous studies, i.e. different water to cement ratio leads to different cracking time $\left(\mathbf{T}_{\mathbf{c}}\right)$ and the higher ratio of water to cement paste need long time to reach its drying at early age $[6,10,18]$. Nevertheless, many of the previous studies did not determine exactly the cracks would happen. There are two major results in this study; one of which is that the crack location was expected beforehand due to utilizing eccentrically sample, which resulted in higher stress intensity at narrow areas pertaining to the geometrical effect. The other major finding is that the cracking time has happened earlier than what has been conducted by other samplers, in terms of considering higher degree of restrain as could be provided by the eccentrically geometry.
Table 4. Mix proportion Inflection and cracking time

\begin{tabular}{|c|c|c|}
\hline Samples & $\begin{array}{c}\text { Infliction time } \\
\text { (Ti)/hours }\end{array}$ & $\begin{array}{c}\text { Cracking time } \\
\text { (Tc)/hours }\end{array}$ \\
\hline P0.3 & 9.2 & 39.708 \\
\hline P0.35 & 9.90 & 51.917 \\
\hline P0.4 & 10.7 & 52.333 \\
\hline P0.45 & 11.5 & 59.05 \\
\hline
\end{tabular}

\subsection{Relationship between Electrical Resistivity and Restrained Shrinkage Crack}

In order to identify the relationship between cracking time (Tc) and electrical resistivity, a mathematical equation is being proposed in this study. The equation has been obtained from linear fitting of resistivity inflection points identified on the curves (as enlisted in Table 4 and shown in Figure 7 of cement pastes and the identical crack times. The relation could be represented by the following equation 1

$$
\mathrm{Tc}=7.5054 \mathrm{Ti}+26.741 .
$$

The regression coefficient $\mathrm{R}^{2}=0.8587$.

Where (Tc) and (Ti) refer to cracking time and inflection times in hours respectively.

This equation can predict the cracking time based on electrical resistivity; it shows that electrical resistivity measurement of cement pastes can be drawn to predict cracks at early age for different water to cement ratios.

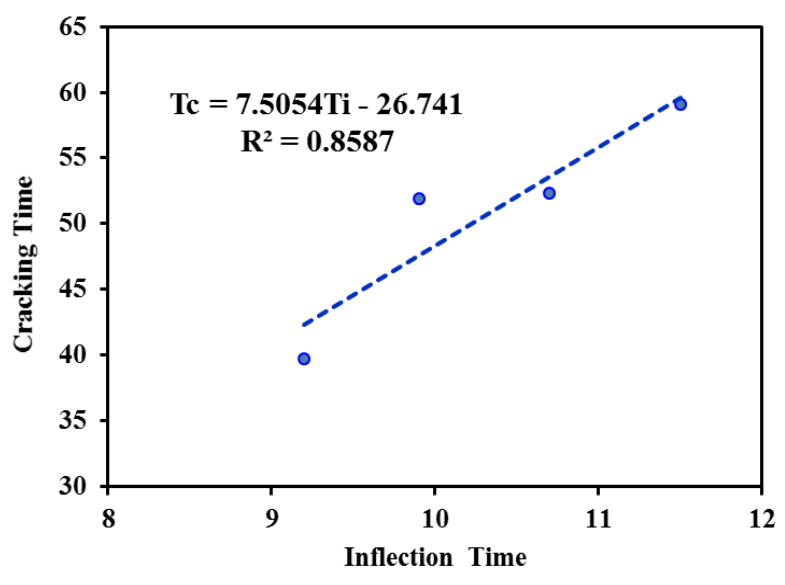

Figure 7. Linear relation between crack time (Tc) and inflection time (Ti)

\section{Conclusions}

In light of the aforementioned results which were acquired throughout the test investigation; the following conclusions can be derived:

1. Electrical resistivity is a good indicator of hydration process of cementitious mixtures and it can predict the strength of the cement paste at early age, it has took the early age ( 3 days) to illustrate this relations and others properties.

2. All experiment's investigations show that the lower water cement ratio pastes cracked earliest than that 
specimens with a higher water to cement ratio. Results obviously indicate there is a relation between crack time and electrical resistivity, and crack time versus the water-cement ratio.

3. Results of Restrained shrinkage behavior by a new eccentrically sample considerably differed from that of other restrained sample such as ring sample.

4. The tendency of cracks that happen at the narrow region of cement paste specimens can be an indicator for eccentrically restrained shrinkage test. The cracks grow at the narrow area, and can further grow to full-depth over time at that area before starting at the wider side.

\section{References}

[1] J. Branston, S. Das, S. Y. Kenno, and C. Taylor, "Influence of basalt fibres on free and restrained plastic shrinkage," Cement and Concrete Composites, vol. 74, pp. 182-190, 2016.

[2] H. Beushausen and N. Bester, "The influence of curing on restrained shrinkage cracking of bonded concrete overlays," Cement and Concrete Research, vol. 87, pp. 87-96, 2016.

[3] ACI224, "Causes, Evaluation, and Repair of Cracks in Concrete Structures," Technical Documents, American Concrete Institute United States, 2007.

[4] H. M. Aktan, G. Fu, W. Dekelbab, and U. Attanayaka, "Investigate causes \& develop methods to minimize early-age deck cracking on Michigan bridge decks," 2003.

[5] M. A. Saadeghvaziri and R. Hadidi, "Cause and control of transverse cracking in concrete bridge decks," 2002.

[6] S. M. Bawa, X. Wei, and L. Wang, "The relationship between electrical resistivity of cement paste and its restrained shrinkage crack with the aid of novel apparatus and ANSYS simulation," KSCE Journal of Civil Engineering, vol. 21, pp. 339-345, 2017.
[7] M. Grzybowski and S. P. Shah, "Shrinkage cracking of fiber reinforced concrete," Materials Journal, vol. 87, pp. 138-148, 1990.

[8] W. Dong, X. Zhou, and Z. Wu, "A fracture mechanics-based method for prediction of cracking of circular and elliptical concrete rings under restrained shrinkage," Engineering Fracture Mechanics, vol. 131, pp. 687-701, 2014.

[9] C. A. Shaeles and K. C. Hover, "Influence of mix proportions and construction operations on plastic shrinkage cracking in thin slabs," Materials Journal, vol. 85, pp. 495-504, 1988.

[10] K. Kovler, J. Sikuler, and A. Bentur, "Restrained shrinkage tests of fibre-reinforced concrete ring specimens: effect of core thermal expansion," Materials and Structures, vol. 26, pp. 231-237, 1993.

[11] F. Collins and J. Sanjayan, "Cracking tendency of alkali-activated slag concrete subjected to restrained shrinkage," Cement and Concrete Research, vol. 30, pp. 791-798, 2000.

[12] AASTHO, "Standard Practice for Estimating the Cracking Tendency of Concrete A Specification" in Designation: , ed. United States, 1997, pp. PP34-99, 1997.

[13] X. Wei and Z. Li, "Early hydration process of Portland cement paste by electrical measurement," Journal of materials in civil engineering, vol. 18, pp. 99-105, 2006.

[14] ASTM"C109-1998". "Test method for compressive strength of hydraulic cement mortars (Using 2-in. or [50-mm] cube specimens)," vol. vol. 04.01, 1998.

[15] C. ASTM, "403/403M-99 (1999) Standard test methods for time of setting of concrete mixtures by penetration resistance," Annual book of ASTM standards, vol. 4, pp. 1-6, 1999.

[16] B. S. Muazu, X. Wei, and L. Wang, "Hydration process and crack tendency of concrete based on resistivity and restrained shrinkage crack," Journal of Wuhan University of Technology-Mater. Sci. Ed., vol. 31, pp. 1026-1030, 2016.

[17] Y. Liao, X. Wei, and G. Li, "Early hydration of calcium sulfoaluminate cement through electrical resistivity measurement and microstructure investigations," Construction and building materials, vol. 25, pp. 1572-1579, 2011.

[18] X. Wei, L. Xiao, and Z. Li, "Electrical measurement to assess hydration process and the porosity formation," Journal of Wuhan University of Technology--Materials Science Edition, vol. 23, pp. 761-766, 2008. 